\title{
Workplace Abuse: Problems And Consequences
}

\author{
Fred Ebeid (E-mail: F-Ebeid@wiu.edu), Western Illinois University \\ Tej Kaul (E-mail: T-Kaul@wiu.edu), Western Illinois University \\ Kathleen Neumann (E-mail: K-Neumann@wiu.edu), Western Illinois University \\ Hugh Shane (E-mail: H-Shane@wiu.edu), Western Illinois University
}

\begin{abstract}
Workplace abuse is a relatively recent phenomenon that affects millions of employee in all types of organizations and occupations. Most of the literature on workplace management deals with employment discrimination and due process. Workplace issues of emotional abuse inflicted on employees by supervisors or managers are seldom addressed. An organization becomes abusive when it permits or tolerates abusive employee treatment by supervisors or managers. In the news each day, the media regularly report on violence facing society such as child, domestic, or elderly abuse. However, workplace abuse is rarely mentioned. As more employees become emotionally and even physically ill as a direct result of the work they do, some employers are examining their workplace management practices. The level of workplace stress has been recently intensified by economic downturn, massive layoffs, mergers, and restructuring. Many organizations worldwide have been forced to cut jobs, resulting in dramatic increase in workplace stress and abuse. This article identifies workplace abuse as an emerging organizational issue by focusing on the problems and consequences for management, employees, and their families. It also provides ideas on how to maintain a healthy workplace.
\end{abstract}

\subsection{Introduction}

W

orkplace abuse is on the increase in many types of organizations and occupations. Harvey Hornstein, author of the book Brutal Bosses and Their Prey, describes today's workplace as, “...some nightmarish school yard - a place where bosses shake down subordinates for their psychic lunch money and then stomp on their egos for sport” (Labich, 1996, p. 3). He also added that, “...on any given day, one of five people will get abused by a boss" (p. $3)$. Workplace abuse by supervisors or managers creates an unhealthy workplace. The inability of some managers to control their abusive behavior results in a hostile work environment for their subordinates. Loss of jobs due to downsizing and in some merger cases has robbed many workers who were retained of their employment security and selfconfidence. *

The Equal Employment Opportunity Commission defines a hostile work environment as, "verbal or nonverbal behavior in the workplace which is biased, unwelcome and pervasive enough to affect a person's work." When workers are exposed to such an environment, conflict between employees and management will emerge leading to serious problems including stress and possibly even workplace violence. Legal consequences of abusive workplace behavior are still evolving. Many cases and incidents of abuse that have occurred in organizations are still not recognized. However, they represent a vast and relatively new source of hostility in the workplace. Sexual harassment is a classic example of workplace abuse. The majority of abusive cases reported recently, however, fall under nonsexual workplace harassment. Henry Platt (1994) indicated that, "one slur or epithet can effectively destroy a working relationship and creates a hostile environment, particularly if the comment is by a direct supervisor" (p. 29). But the courts have little jurisdiction to hold employers liable for the abuse based on isolated or scarce contemptuous remarks in the workplace. This lack of jurisdiction or legal protection has given employers and supervisors/managers an escape path for abusive or hostile behavior.

\footnotetext{
* Organizations, employers, bosses, managers, and supervisors are used interchangeably in this article as sources of authority that can inflict abuse on employees/workers/subordinates.
} 


\subsection{What is Workplace Abuse?}

An organization/employer that makes employees do what management wants through fear, intimidation and coercion, is described as abusive. Abusive organizations operate with callous disregard for their employees, not even displaying what might be a minimum amount of concern for their human needs (Powell, 1998, p. 95). As a result of current trends of downsizing, rightsizing, reengineering and layoff, employees put up with abuse because of concern about job security. Because many employees who are not laid off fear further downsizing, they tolerate abusive treatment (Powell, 1998, p. 95). Employees who remain at such organizations are faced with increased pressure to complete the same amount of work as before, but with fewer employees.

Workplace abuse is the brutalizing and dehumanizing of an employee at work by a superior (Wyatt \& Hare, 1998, p. 1). Job stress used to be synonymous with work abuse, but it is when stress is the direct result of managerial or supervisory practices aimed at gaining control of an employee that it becomes work abuse. Work abuse is not just targeted at individuals at lower levels. It can also be directed at managers, supervisors, and entire units/departments. It is not hard work that causes managers the greatest amount of stress. Most accept long hours and pressured deadlines as part of the job. What triggers harrowing days and sleepless nights is a syndrome that can be called impossible expectations by an organization/employer. Managers suffering from it are asked by their bosses to solve problems, but then do not receive the tools, resources or authority that will enable them to do that (Hymowitz, 2001, p. B1). As Chere Estrin (1996) concluded in her research on emotional abuse in the workplace, "...the great silent secret of the American workplace is that emotional abuse is a far more pervasive problem than sexual, age or race discrimination" (p. 1). In the U.S., there are laws that protect employees against discrimination in employment. However, such laws do not address emotional work abuse. An organization that subjects employees to oppressive emotional working conditions is abusive.

In an abusive workplace environment, employees are subjected to behaviors and actions by supervisors that adversely affect their ability to function effectively in their jobs. Abusive organizations may not be in violation of existing laws because they are not engaged in discrimination or workplace safety violations. Rather, workplace abuse is primarily emotional in nature and as such may be difficult to challenge legally. Emotional abuse take many forms and affects employees in various occupations and settings. As Daniel Costello (2001) wrote, “...first there was road rage, then air rage. Now there is desk rage. A new economy cocktail of longer hours, increase workloads and stock-market tremors is fueling explosions of tempers even in once-staid offices. Companies generally do not report instances of worker confrontations, but occupational experts and authorities on workplace stress say that the number of incidents is rising, along with their severity" (p. B1).

In addition to abuse by managers/supervisors causing overwork, family issues and health-related concerns are adding to employee stress. Job overload, economic downturn, mergers, downsizing and the ability of managers to monitor individuals' job performance add more layers of insecurity. As workers worry about layoffs, they do so knowing that the new information technology allows their managers to track performance division-by-division, employee-byemployee, and with startling precision (Hymowotz, 2001, p. B1). Victor Scarano, Director of Occupational and Forensic Psychiatry at Baylor College of Medicine in House, pins much of the blame on the stress induced by overwork. You "cannot run an engine at full throttle for 10 years and not expect it to crack, Scarano say" (Costello, 2001, p. B1).

\subsection{Causes of Workplace Abuse}

The causes of abuse in organizations are vast and immense. The abuse of employees could come from many angles. Sometimes, the things that are deemed impossible to be true by ordinary standards are the reality in the workplace. There is never a good time to lose a job, says Katherine Sopranos (1998). Nevertheless, employees do get terminated during the holiday season for reason like plant closing, acquisitions and mergers (Sopranos, p. 1).

The environment of a workplace or a corporate culture could mean the difference between a conducive or abusive workplace. According to Perez Moroz and Brian Kleiner (1994), "Hardball is the term used for the achievement and preservation of power that is useful in any profession" (p. 9). Where there exists a competitive organization structure, there are a few individuals who have the power to command. It is sometimes the structure of an organization 
and the mindset of those few individuals that lead to the creation of the "monster" known as [the] abusive organization. Condoned by the structure of organizations, those few individuals will pursue and use their status and power to compensate for or secure their positions. The goal of those who have power is to attain personal well-being and comfort. Consequently, to achieve this comfort, these individuals popularly known as management, abuse their power as a way to get things accomplished. According to Bassman and London (1993), there are no standard guidelines for the treatment of subordinates abused by supervisors/managers in many firms. The pressure to preserve their respective positions in an organization may prompt these managers to abuse their subordinates (p. 18). However, the reasons managers are abusive may not stem from fear of losing their power alone but can be also triggered by personality disorder, job stress, and learned violence. Such managers will promote undeserving subordinates on the bases of nepotism while taking advantage of a company payoff for their private lives.

A manager who exhibits abusive behavior may have considerable self-confidence and some managerial skills to cover up this "gray" behavior. The benefits of abuse may also stem from personal gratification - that is, a manager may feel more in control and have an attitude of superiority. The abuse inflicted may take the form of public ridicule, disrespect, overwork, and overcontrol. Sometimes a manager may get so stressful, the abuse may involve making poorly planned changes and unrealistic or unfair demands, such as forcing one subordinate to do another subordinate's work in addition to his or her own. Showing favoritism by a manager creates the greatest obstruction in decision-making. Subordinates are dependent on their superior for rewards, work structure and job security. But showing favoritism by any superior will exclude some subordinates from opportunities for development and advancement. The means of achieving goals by a superior or manager is of prime importance, even if it leads to abuse of subordinates (Bassman \& London, 1993, p. 18).

Work environments that require a seamless flow of operation such as in assembly plants, telemarketing, and brokerage firms are candidates for becoming abusive organizations. Many supervisors who manage such workplaces emphasize the policy of work first and workers' well-being second. Supervisors seem to think that once workers are in the perimeter of the work zone, they are subject to control by management. For example, manufacturing plants are required to provide an appropriate number of toilet facilities based on the number of workers. However, the availability of such facilities does not guarantee their reasonable use by employees in certain workplaces (Linder, 1998, p. S3). Restrictions on the use the toilets are often imposed on assembly line and construction workers by supervisors. It is the culture of such organizations that many assembly line employees have to work in a hostile environment. Many times workers feel they must accept their work environment simply because if they leave the job, their next job would still be in the same or nearly identical workplace. In such cases, workers seldom rebel and often comply.

Learned association like stereotyping which is based on negative and positive sets of beliefs about a certain group have helped to sharpen the edges of abuse in organizations. Stereotyping often bears the shade of discrimination. There is no doubt in today's workplace that either stereotyping or discrimination persists in organizations. The existence of this behavior may not be intentionally pursued but it could still be present even within a respectable, well-known organization. An organization does not need to condone the act of worker abuse. However, just a minor unsupervised behavior carried out by a certain person is sufficient to create a hostile work environment. When such a breeding ground for hostile and abusive practices is not eliminated, a chain of abusive incidents will evolve.

The source of discrimination in an organization sometimes comes from the most influential unit, Human Resources. Discrimination by human resource professionals takes many forms such as unfair application of policies, ambush of workers, and unregulated personnel actions by supervisors. Organizational policies sometime overlook certain groups of workers while claiming to protect others. Hence, such bias in the workplace unintentionally creates a hostile work environment (Wendt \& Slonaker, 1992, p. 44). Policies such as promoting the hiring of job applicants at age 35 or under with less than 10 years of work experience, have profound adverse effect on employees over age 40 (Hundley, 1992, p. 74). This form of age discrimination tends to intimidate employees in the hope that they will find the workplace unbearable, and voluntarily leave their current employer. 
Many managers recognize the activity of hazing at work. It involves rites of passage for newly hired workers. Since this becomes part of a workplace norm or culture, hazing is "tolerated" by organizations as necessary for newcomers in order to be accepted by coworkers and superiors (Josefowitz \& Gadon, 1998, p. 22).

Perhaps one of the most flagrant abuses is ambush against the disabled. Often an employer has already decided to discharge an employee, but will wait for the right situation to use as the cause of termination (Wendt \& Slonaker, 1992, p. 44). Whatever their source, each hostile encounter in some way constrains employees options or threaten their control over important outcomes.

Today, many employers are known for their family-friendly orientation. Childcare, nursery, and insurance benefits are designed to ease family burdens. All these new approaches have helped raise employees' motivation at work. However, what is deemed friendly to some may be down right unfriendly to others who do not fit the mold. Organizations that are family-friendly often require their single employees to cover up for parental-leave, sick-child care, and other family-only-employees "goodies." Single employees in these organizations are also asked to work overtime, make last minute transportation arrangements, and take additional assignments just because "they are single." So when do "single" employees get their breaks? One might think that "single" employees might have greater chance for promotion since they have the flexibility to deal with unexpected work schedules and assignments. Well, one should think again because often times, that is not the case. As Diane Harris (1995) has noted, the top management positions are often reserved for those who are married (p. 120). In this instance, not only do single employees have a larger share of late night work schedules/shifts, they also receive the lower share of promotions. Family-friendly policies should be defined as flexible policies, not special privileges (Brackin, 1996, p. 104). Balancing work and life should be a commitment for all members of an organization, not just for a certain group of employees. Further, employees should be recognized for their performance and contributions, not for their marital status when making promotion/advancement decisions.

Certain jobs require work accommodations that affect many single employees such as "managing" office romance. Some managers believe in regulating office romance. According to Michael Lawrence and Tracy Thornburg (1996), in the Boaden versus Department of Law Enforcement case, when a police trooper told her supervisor that she is engaged to another trooper who also worked on the same shift, the supervisor suggested a transfer before her marriage (p. 5). The rigid protocol of the police department in this situation is an example whereby a couple working in the same place is forced to change jobs or accept a transfer. Is it legitimate to make a work assignment/schedule on the basis of an employee's marital status? While some organizations may have their own "marital protocol," it should not be used as a type of punishment if two employees do fall in love. Organizations should be helping their employees to attain prosperous lives, not punish them when they are planning to get married.

Sometimes work policies that require employees to be adaptable and flexible can create a hostile workplace. However, certain expectations that are being underlined as crucial to the development of an organization can be deemed hostile to female employees and executives. Take for example when a female student is working in a grocery store that requires her to smile and greet every customer that comes into the store. Although smiling and greeting are common and expected in a service work environment, some male customers can misinterpret them. In this situation, the female employee behavior may invite undesirable encounters. Her employer has in effect created a hostile workplace for female workers. Rarely will an employer spot employees being pursued by customer while working, and it will be even harder for a female worker to approach her employer to voice a complaint. For we all know, the employer or organization that emphasizes customer service will almost always believe the customer "is always right." When such negligence occurs, the well-being of employees is discounted in order to achieve higher customer service and sales.

The incidents of abuse also happen at the top level of the organizational pyramid. "Being at the top is like playing a guessing game in the dark for many women," claims Diane Harris (1995, p. 120). The higher a person is at in the organizational hierarchy, the more "chemistry/being part of a special club" is required to do a job. For many women, the lack of this so-called chemistry can translate into not having access to the thinking of top management. 
Although, some organizations do not specify performance quality in their job criteria, the pervasiveness of such standards exerts conformity on the part of employees. Also, the lack of criteria may crush hope and limit opportunity to succeed. Let us say there are a few women who conform and meet their organization performance quality standards. Will they still have an equal chance to advance in the organization? The fact of the matter is that many women are afraid to change the corporate culture for fear of punishment. Even though a few women can prove themselves to be "corporate-worthy," those with children will continue to be discriminated against in their careers (Harris, 1995, p. 120).

Perhaps the most well known case of sexual harassment in today's context is the recent settlement of the Mitsubishi case. One of the most unique aspects of this case was the sexist attitude of male workers that were tolerated by management. Also, the solution that was given by the company was "retaliated terror against women who complained" (Annin \& McCormick, 1997, p. 50). The case was settled with the payment of \$34 million to the victims, and an effort of intense reform to change male workers' attitudes. However, Mitsubishi has yet to achieve its reform plan, but women remain afraid to complain when things get out of hand. Women continue to witness, "Other women [being] ostracized or threatened for speaking up" (Annin \& McCormick, 1997, p. 52).

Sexual harassment not only happens to female workers. Male employees are sometimes overlooked by an organization's policies. For instance, a male employee may be fired simply because he failed to report tardiness. Male employees who fall short according to policies often do not receive counseling and a written warning because "only females get progressive discipline" to avoid sexual harassment cases (Wendt \& Slonaker, 1992, p. 45). Perhaps like the pendulum that swings both ways, "bad bosses tend to be equal opportunity abusers" (Loeb, 1996, p. 3).

\subsection{The Abusive Organization: Problems}

An abusive organization or abusive supervision create many serious problems and produces a number of dysfunctional consequences. In one study, abusive supervision was defined as, “...subordinates' perceptions of the extent to which supervisors engage in the sustained display of hostile verbal and nonverbal behaviors, excluding physical contact" (Tepper, 2000, p. 178). Abusive supervision may take the form of public criticism or ridicule of subordinates, loud and angry rage targeted at employees, rudeness in dealing with subordinates, and coercion of employees to achieve certain levels of performance (Tepper, 2000, p. 179).

There is a fine line between an abusive and a discriminatory organization, and it is therefore difficult for people to distinguish between the two. An organization that violates existing employment laws and directives is engaging in discrimination. An abusive organization may not be in violation of anti-discrimination legislation or executive orders. Existing employment laws or directives do not protect employees in an abusive organization. While abusive organizations do not discriminate against their employees, they foster a hostile work environment. In such organizations employees feel threatened by their supervisors and possibly their co-workers. There is general disrespect for employees in abusive organizations.

Recent trends in downsizing have led to layoffs and terminations, mergers and acquisitions - all of which have resulted in new employee performance measures and added stress. As a direct result of such trends, supervisors have assumed more power and control over their subordinates. Abusive organizations "force" their employees to work more hours and produce more with less resources. For fear of further downsizing, many employees who are retained by these organizations "cope with and endure" abuse. Often times, these employees are so desperate to keep their jobs that, "they are willing to accept abusive treatment in the short run to increase the chance of holding onto their jobs in the long run" (Powell , 1998, p. 5).

Managers may use a variety of ways in abusing subordinates including coercion, intimidation, derision, and vindictiveness (Bassman \& London, 1993, p. 1). Although an abusive organization may not allow harassment of employees as defined by law, other more subtle types of harassment may be tolerated or even overlooked. For example, an employer may permit employees to display offensive posters or cartoons in the workplace. Employees might also tell jokes or make remarks regarding people of the opposite sex, different racial backgrounds, or different religious preference. Some employees may feel offended or even threatened by such behavior and feel alienated because of a 
hostile work environment. These employees may experience unnecessary stress as a result of such behaviors. "Stress is the number one injury in the workplace," says Jerome Franklin, a noted Beverly Hills, CA, psychiatrist (Estrin, 1996, p. 2).

While this disregard for employees' feelings is a major issue in abusive organizations, it may lead to a much more serious problem - workplace violence. By neglecting to address employees' concerns and emotional well being, abusive organizations are creating dangerous work environments. Employees who feel mistreated at work might resort to violence. This can ultimately threaten the safety of the workplace for all employees, including supervisors.

In abusive organizations employees might be criticized by supervisors in the presence of their co-workers for performance-related issues. Confronting subordinates in front of their colleagues is disrespectful and impacts negatively on their job success. This belittles employees and can cause them to experience high levels of psychological stress. Furthermore, "a disrespectful attitude disables communication" (Darling, 1994, p. 70).

Downsizing has led to an increase in the number of abusive organizations. These organizations tend to be understaffed resulting in employee work overload. Performance appraisal in abusive organizations often focuses on quantitative measures. The workplace is very demanding and emphasis is on productivity and meeting performance targets and deadlines. This can lead to added job stress. Employees are required to perform their tasks in a timely and efficient manner but often are not given the necessary resources to do so. As a result, employees may experience uncertainty about their roles, tasks, or job expectations. When employees are unable to meet job expectations, they are often ridiculed by their supervisors and treated harshly. Because they are subjected to this type of abuse, employees experience lack of self-confidence and feel worthless or incompetent. This can lead to extreme job stress.

Abusive organizations neglect their employees' needs to balance work and family. "Some abusive organizations even have the gall to brag about their work-family programs, but only pay lip service to the notion and promote such programs just for public relations value" (Powell, 1998, p. 95). In some of these organizations, family-friendly programs are in place but employees are penalized or ridiculed for using them. In reality, abusive organizations are "discriminating" against employees with dependent or elderly care needs by punishing them for using family-friendly benefits. For example, a company might offer its employees a flex-time scheduling plan that allows them to work anywhere between the hours of 7 and 9 a.m., and then hold a required employee meeting at 8 a.m. without informing them in advance. Those who do not attend will be penalized. While any employee could be the victim of this type of abuse, it affects women more often than men because mothers tend to be the ones who manage dependent care needs. Hence, many women believe that they are not promoted as often as they should be because of these unwritten rules that punish employees for taking advantage of the family-friendly programs (Caudron, 1994, p. 33).

\subsection{The Abusive Organization: Consequences}

Workplace abuse by supervisors/managers has a serious impact on job performance of workers who report directly to them. A substantial problem exists in terms of the definition of supervisor or organization abuse. According to Gary Powell (1998), "[the] abusive organization has little regards for its employees, not even displaying what might be considered a minimum amount of concern for their human needs" (p. 95). Organizations are able to get away with abusing their employees more easily during a declining economy. Hence, the connection between the "callous" abuse of employees and "nasty" bosses defines an abusive organization.

Brutal bosses often scrutinize the work performed by subordinates. Intrusive electronic surveillance is on the rise (Labich, 1996, p. 3). This can build up the emotional trauma suffered by employees. Emotional abuse in the workplace has become so pervasive that it is considered by many as the norm (Estrin, 1996, p. 78). Emotional abuse is perhaps the cruelest of all inhumane acts by superiors. Because of the fear of retrenchment, employees are willing to accept abusive treatment like harassment, criticism, and public humiliation in return for holding on to their jobs. Many employers are aware of that. Consequently, many of them continue to push their employees, and push them regularly to have as much work done as possible. This has become the routine for many employees who remain in such organizations. 
In today's business environment, the workplace influences the level of productivity generated by workers. An abusive organization will never achieve the desired level of productivity. The effects that these organizations have on their workers are abstruse. United States businesses are losing five to six billion dollars annually in diminishing productivity. "This condition is serious, pervasive and expansive. It is defined as the actual disintegration of an employee's fundamental self' (Wilson, 1991, p. 47).

The premise that hostile workplaces influence employees' productivity is a psychology stressor. Of the many barriers to the development of an employee career, workplace trauma is among the most predominant psychological effect. Often times “....an employer's or a superior's perceived or real continual deliberate malicious treatment is workplace trauma" (Wilson, 1991, p. 47). According to Bassman and London (1993), when doing what were required by their superiors do not constitute a better workplace, then employees will often start to react to workplace abuse. This may include increased efforts to meet employers' expectations or withdrawal from the situation or a combination of these behaviors (p. 18).

As the strained relationship between employees and management is prolonged in the abusive organization, the cost of maintaining the business will rise while workforce productivity will decline. Decreased productivity is not the only problem here. Billions more are lost as result of an abusive workplace from wrongful termination, lawsuits, and compensation costs (Wilson, 1991, p. 47).

When the workplace becomes hostile, it opens the door to workplace trauma. This is a condition whereby employees' performance start to decline and is followed by an increase in absenteeism and turnover. When employees are forced to do something that they and/or their organizations do not support, their jobs performance will suffer. Increasingly, when employees are being harassed and abused by their bosses, it is human nature to avoid the situation. As claimed by Bassman and London (1993), "each reaction [by an employee] is likely to lessen [the] subordinate's job performance, job involvement, organizational commitment, and career motivation" (p. 18).

Communication breakdowns caused by stress often result in lost or inaccurate information. The effects of isolation, one form of power and control, add to many women employees' self-consciousness and lowered self-esteem. When top management does not treat improper behavior within the context of the victims, communication will fail to reduce discrimination and harassment in the workplace (Verespej, 1997, p. 24).

During an economic downturn, some organizations are barbarous in their downsizing strategy. Claim of favoritism and lack of empathy are deemed acceptable in these organizations. It also seems that whenever there is a wave for downsizing, brutal bosses often find themselves possessing unrestrained power to fire employees. Holding on to their power, many employers cut jobs, thus bringing uncertainty to the workplace. As noted by Carla Joinson (1997), "downsizing with all the extra work and worry it produces places constant stress [on] employees" (p. 85). Perhaps even more apprehensive are the outcomes of irritability and short tempers among employees. "Even good people, well-trained, and selected can slip in the courtesy factor" (Joinson, 1997, p. 85).

The great "silence is golden" saying has outraged many emotionally abused employees. Since no arms or bones are broken and no harsh comments are heard, it was hard to realize the impact of abuse on employees. The cover up of emotional distress increases turnover, lost jobs, lost productivity and destroys morale in the workplace (Estrin, 1996, p. 78). While the effect on the organization may be small, the damage inflicted on the employees is permanent and deep. As quoted by Jerome Franklin, “...stress is the number one injury in the workplace” (Estrin, 1996, p. 78). Employees who are victimized often pay for workplace abuse in a substantive way in terms of emotional and other health related consequences. These victims regularly suffer anxiety, depression, heart problems, gastrointestinal disorder, headaches, skin rashes, insomnia, and sexual dysfunction (Labich, 1996, p. 3). Clearly, the invisible nature of workplace abuse is as serious as physical occupational injuries.

The hardest time for employees to lose their jobs and income is during the holiday season. This further aggravates the stress level terminated employees experience. The gift giving and sharing associated with the holiday season, and the anxiousness to find a new job add up to major emotional distress. The loss of confidence, the threat of 
losing jobs, and emotional distress are few of the most profound effects on employees. As noted by Brady Wilson (1991), such "...contamination in the employment process clearly falls under the domain of posttraumatic stress disorder" (p. 4). Many abused workers are loath to speak out publicly on their personal experiences. In some cases, they believe it is too demeaning or embarrassing. Many workers, however, elect to just shut (workplace abuse) it off and continue to pursue their careers, hoping that things might be better in future. Shutting off what workers feel is not right, is one way of dealing with workplace abuse. "One reason abuse works is that people are generally obedient to authority" (Bassman \& London, 1993, p. 18). This passive response to abuse by employees has allowed bosses to continue their acts. And, the hope that things might be better the next time will be carried forward and there may never be improvements in the workplace.

Sometimes the effect of abuse takes a greater toll than previously described, whereby abused employees begin to blame themselves for their employers' behavior. At some point, these employees tend to project their abuse into many facets of their professional and personal lives. This helpless behavior will "further decrease the subordinate's selfconfidence" (Bassman \& London, 1993, p. 18). According to these authors, feeling helpless in many situations is a type of human depression. Although employees can fight back to restore their loss of control, their actions may project more negative consequences. Hence, employees are less likely to choose confrontation.

Although many litigants decry incidents of employment discrimination, sexual harassment, and unsafe/hazardous working conditions, there is very little attention given to emotional abuse and the terrible toll it cost employees and their families. "While it may be much easier to be outraged by physical violence or blatant harassment, emotional abuse does exist in the workplace - and it exacts a huge penalty in terms of turnovers, lost productivity and destroyed morale" (Estrin, 1996, p. 1). Managers/supervisors who are able to recognize when an abusive organization becomes a discriminatory one will be able to prevent it from becoming discriminatory, and they might even be able to create a healthy work environment for their employees. On the other hand, managers who fail to detect when an abusive organization turns discriminatory will be faced with lawsuits.

In his extensive research study, Bennett Tepper (2000) conclude that “....subordinates whose supervisors were more abusive reported higher turnovers, less favorable attitudes toward jobs, life and organizations, greater conflict between work and family life, and greater psychological distress" (p. 186). Workplace abuse is a silent occurrence in organizations that practice or tolerated it. Abuse can have detrimental and lasting effects on the victims (employees) as well as their families. Work abuse dehumanizes the victim and creates an environment of self-worthlessness, and promotes a sense of denial that it is even an issue in the first place. Work abuse may lead to child, spousal and dependent elderly abuse. Abused employees may dehumanize their loved ones to fill the need to feel important only to unknowingly create a pattern of abuse in the family.

Measuring the financial cost of workplace abuse is somewhat difficult because of lack of litigation and court decisions. Still there are many areas that can be examined in terms of the cost to abusive organizations. These include production loss, turnover, sick leave, work-related injuries, and competitive advantage status. The cost of abuse to the victims and their families cannot be compared to the large monetary cost organizations may face if lawsuits are filed. The primary cost to victims of workplace abuse is that of emotional and physical health problems such as stress, depression, sleep disorder and mental illness. Besides the physical problems victims suffer, they tend to develops a lack of self-esteem, a loss of personal confidence, lack of motivation, become anxious or irritable, or possibly turn to drugs or alcohol to alleviate their symptoms (Chappell \& Di Martino).

The consequences of workplace abuse can also be devastating for a victim's family. Bennett Tepper (2000) expressed them in these terms, “...preoccupation with work-related matters causes the time the victim spends with his or her family to be adversely affected" (p. 178). Children are very vulnerable to parent mental and physical situation/status. If employees feel degraded/disrespected in the workplace, they may "compensate for the loss of self-worthlessness" by mistreating their children.

Abusive organizations must pay attention to the impact of emotional and physical consequences their managerial practices have on their employees. As Tepper (2000) concluded, “... the potential harm associated with abusive 
supervision ought to serve as a warning to organizations. Employees regard abusive supervision as a source of injustice that, in turn, has implications for their attitudes and well-being. The consequences of poor moral are well documented and include absenteeism, turnover, and reduced performance of extra role behaviors. The links between abusive supervision and the various indexes of psychological distress are also troubling because even the milder manifestations may engender significant social and financial costs to organizations (p. 186).

\subsection{Establishing and Maintaining a Healthy Work Environment}

While stress is a normal part of professional and personal life, workplace abuse in any form and from any source, should not be tolerated and must be forcefully dealt with. Although many work-related abuses do not fall under employee-protected rights such as equal employment, due process, and safety, it could, if not dealt with, lead to emotional and serious physical problems for employees.

The changing workplace of the last two decades has created new challenges for many organizations. In order to remain competitive, managers must learn to distinguish between an abusive and a discriminatory organization. They must realize that abuse will eventually result in employee discrimination leading to costly medical treatment and litigation. Management's ultimate goal should be to create a healthy work environment where all members of the organization are valued and respected.

The first step toward establishing and maintaining a healthy organization is for management to develop a written plan of "zero tolerance" for dealing with any type or form of discrimination and workplace abuse. This policy must be committed to by top officials of an organization as part of its vision and strategic human resource planning. In the U.S., while the federal and most state governments encourage businesses to establish a zero tolerance policy, many employers do not do so and will probably not have one until confronted with a crisis. But even if a zero tolerance policy does exist, management may not enforce it. It is absolutely essential for top management to support the policy, which will make a difference in employees' perception of how serious the organization is about maintaining a healthy workplace.

Organization culture is key to the establishment of an abuse-free workplace. A workplace culture that promotes concern for employees' work and family needs is viewed by all members of the organization as a great place to work. A healthy organization takes employees' needs into consideration at all times. This type of organization goes beyond what is required by law to make employees feel welcomed, respected and valued. Input from employees is encouraged in the decision making process. The workplace environment is participative and supportive. There is an excellent professional relationship between management and employees - a team-like work environment. Supervisors are supportive and their leadership styles are inspirational. Managers identify and remove performance obstacles to facilitate employee accomplishment of job tasks, and provide the necessary training when needed. Employees in healthy organizations are recognized and rewarded for their individual and team achievements. There is a feeling of a supportive and caring work community. As a result, employee moral and job satisfaction tend to be high.

Education and training programs are needed to overcome workplace abuse. Managers and employees should participate in such programs where they learn what is acceptable behavior and conduct in the workplace. Performance evaluations and rewards should be linked to maintaining an abuse-free healthy work environment. Management training programs can help supervisors recognize and deal with abuse, development programs can treat abusive supervision, good management practices can help alleviate or avoid abuse, and employee assistance programs can improve abusive supervisors' behavior (Bassman \& London, 1993, p. 6). Upon hiring, employees in healthy organizations are enrolled in a mentoring program to help ease their job transition. Each new employee is assigned an experienced mentor. Employees are also provided with numerous training opportunities. Employee Assistance Programs are available for those experiencing work-related or personal stress.

In healthy organizations, employees have a balanced workload. The demands of the job do not exceed employee's abilities. At such organizations, wellness/recreation centers might be available as part of employee services to promote fitness and alleviate stress. Employees also are encouraged to take advantage of flexible work scheduling. Employee and family-friendly policies are well established and clearly communicated. Programs such as childcare and 
elder care, paternity leave, adoption assistance and family leave are provided. Other benefits might include subsidized childcare during school holidays or the provision of on-site day care facilities. Companies might also provide free emergency back up childcare when the primary care situations fall through, allow employees to accumulate and use various paid personal leave time for parental leave following the birth, adoption, or foster care placement of a child, or allow employees to use sick days (in addition to personal and vacation days) to care for sick children or other family member. If employees' children are involved in activities after school, they might be permitted to leave work early; then make up the time by taking shorter lunch breaks or arriving early or staying later at work.

Flexibility in scheduling and work arrangements is common in healthy organizations. Employees are allowed to come in to work earlier or work later to better fit the hours of the childcare center. Often times, employees are provided with the opportunity to work part-time from home. Other options might include telecommuting, job sharing opportunities, or compressed workweeks. Employees might also be permitted to take half-hour lunch breaks in exchange for a day off every four weeks. While the desire for flexible work arrangements is typically created because of the need to attend to family matters such as child and elder care, many employees desire the flexibility because it provides them with the opportunity to volunteer in their communities, commute during less congested travel hours, exercise before going to work, or take a college course. "However varied the reasons for wanting flexibility, the payback to organizations that provide it has been consistent: improved moral and productivity, both from the employees' perspective and that of management. The challenge today is to turn common sense into common practice" (Rose, 1996, p. 16).

The once traditional family pattern of the "breadwinner" father, "homemaker" mother and children is now a minority form in much of the industrialized world (Vine, 1997, p. 12). Healthy organizations realize to keep their employees satisfied they need to create a flexible work environment. To keep employees happy, organizations must allow them to lead balanced lives. Organizations that fail to create a flexible work conditions risk losing skilled, experienced, competent, dedicated, and hard-working employees. "The challenge for the nineties is to find new ways to balance work and home for both men and women (Vine, 1997, p. 13). Broadly what is needed is flexibility of hours and conditions, to make it possible to balance work and family, and indeed, other interests and responsibilities outside of the corporation (Working mothers, 1997, p. 8). The goal is to find the appropriate and reasonable fit between the organization objectives and its employees work and family needs. Employees should not be "forced" to choose between work and family. They should not have to sacrifice their family lives to be successful at work. Both work and family are essential to an employee. Organizations should value the importance of family and make reasonable accommodations when necessary. Anything that an employer can do to help employees balance career and family will benefit all parties involved. When employers establish employee and family-friendly work environments, the employees are happier, more productive and experience less job stress. Creating employee and family-friendly workplaces make good business sense.

It makes perfect sense to build flexibility into the organizational culture (Battman, 1997, p. 4). It also makes economic sense. Rather than losing knowledgeable employees, businesses need to develop programs recognizing the value of working parents. By failing to do so, organizations are alienating a significant amount of today's workforce. Employers must take employees' family needs into consideration. Employees are often required to make tradeoffs in their efforts to balance work and family demands/needs. Adopting and building flexibility into the organization's culture can minimize these tradeoffs.

To help prevent abuse, organizations need to incorporate policies against it into the performance evaluation and reward system of supervisors. Estrin (1996) discussed the role of corporate management in dealing with workplace abuse by stating, “...ultimately, emotional abuse is a management problem, and must be addressed by firm leadership in a larger context. Real solutions to this costly behavior are systematic, involving: overt and consistent recognition by management; breaking the silence that surrounds such incidents to promote open airing of employee concerns; creating a firm-wide policy not to accept abuse under any circumstances; and opening communication channels to give sustained life to the new non-toleration policy" (p. 2).

A healthy organization constantly strives to improve the workplace. All employees are treated with dignity and respect and their views are always valued. The benefits to the organization are numerous: reduced employee turnover 
and greater employee loyalty: lower level of absenteeism, increased employee and customer satisfaction, improved product/service quality, increased productivity, and increase profits.

\subsection{Conclusion}

If we could tell the world just one thing - would it be that we are all okay? With unforeseen changes in the $21^{\text {st }}$ century, will the workplace be a kinder and friendlier environment? The workplace has seen dramatic transformations in the last two decades as a result of economic, political, technological, and social changes. Business as usual does not mean work as usual. Supervisor abuse, emotional stress, and hostile work environment have given rise to a new corporate culture. In fact, it is hard to know where and how the culture has evolved. After all, abusive managers and brutal bosses do not carve their titles on their forehead to warn their employees of their behavior.

An organization's human resource policies can also be inappropriately stated and enforced. They may either focus too much on one group of employees, one type of harassment, or be so general that they provide little guidance in the workplace. Gaps may also exits between policies and realities. The isolated or single incident is not always the problem. Like the saying, "no raindrop considers itself responsible for the flood." It is the culture of incidents - a period of small insignificant occurrences that create an abusive, hostile, and employee unfriendly work environment.

Incidences of workplace abuse are still not widely reported. In many situations, the abuse is either locked behind closed doors or buried inside a victim's mind. The occasion, timing and place of abuse are often unpredictable. Abuse may be in the form of a sudden notice of job loss or directive from management to increase productivity and enhance work performance. Whichever the case might be, the work style and performance of an employee may be adversely affected. One employee may be more self-confidence, but another one who is more sensitive will tend to lose self-esteem and self-confidence. The learned behavior - that it is a victim's fault that caused the abuse - aggravates the impact.

Although this paper discusses the problems and consequences of employee abuse by supervisors or managers, the impact of such behavior will be felt by the entire organization. We many not know exactly how it really affects the organization as a whole, but loss of productivity caused by the abuse and a hostile workplace will translate into financial liabilities in the long term. When acts of abuse are uncovered and reported, the enormous negative publicity alone may damage an organization's image and its public relations.

Workplace abuse is definitely not a conquest of managers and bosses. The prevalence of abuse can only damage the workplace and hurt company productivity. The absolute power and control that is held firmly by supervisors or manager of an abusive organization is a threat to the employer, employees, their families, and to society. It must be addressed in order to maintain and promote a healthier workplace.

\section{References}

1. Annin, P., \& McCormick, J. (1997, November). More than a tune-up. Newsweek 24, 50-52.

2. Bassman, E., \& London, M. (1993). Abusive managerial behavior. Leadership and Organization Development Journal, 18-24. ABI/Inform (1998, June). CD-ROM. Information Access.

3. Battman, R. (1997, August). Industry should grow up and help working parents." Marketing, 14.

4. $\quad$ Brackin, M. (1996, November). Letter. Personnel Journal, 104.

5. $\quad$ Caudron, S. (1994, July). The concrete ceiling. Industry Week, 243(13), 31-36.

6. Chappell, D. \& Di Martino, V. Safework: Violence at work. From the World Wide Web: http://www.ilo.org/public/english/protection/safework/violence.

7. Costello, D. (2001, January 16). Incidents of desk rage disrupt America's offices. The Wall Street Journal, p. B1.

8. Darling, M. (1994, November). Coaching people through difficult times. HR Magazine, 10-73.

9. Estrin, C. B. (1996, March/April). Emotional abuse in the workplace. Legal Assistant Today, 1(2), 78-79. ABI/Inform (1998, June). CD-ROM. Information Access. 
10. Harris, D. C. (1995, September). Grease the gears of equality. Personal Journal, 120-127. ABI/Inform (1998, June). CD-ROM. Information Access.

11. Hundley, J. R. (1992, October). Age discrimination cannot continue. HR Magazine, 74-76.

12. Hymowitz, C. (2001, January 16). Impossible expectations and unfulfilling work stress manager, too. The Wall Street Journal, $p$. B1.

13. Joinson, C. (1997, February). A return to good manners. HR Magazine, 85-89.

14. Josefowitz, N., \& Gadon, H. (1998, May/June). Hazing: Uncovering one of the best kept secrets of the workplace. Business Horizons, 22-26. ABI/Inform (1998, June). CD-ROM. Information Access.

15. Labich, K. (1996, March). Psycho bosses from hell (Review of Brutal Bosses and Their Prey by Harvey Hornstein) Fortune, 18, 3.

16. Lawrence, M. A., \& Thornburg, T.L. (1996, April). Employment law. The National Law Journal, 1, B5, B8.

17. Linder, M. (1998, February 22). A fight for restroom rights. New York Times, p. S3.

18. Loeb, M. (1996, May 27). The bad boss gets a new life. Fortune, 129.

19. Moroz, P., \& Kleiner, B.H. (1994, January/February). Playing hardball in business organization. Industrial Management, 9-11. ABI/Inform (1998, June). CD-ROM. Information Access.

20. Platt, H. A. (1994, March). Nonsexual harassment claims hit HR's desk. HR Magazine, 29-34.

21. Powell, G. N. (1998). The abusive organization. Academy of Management Executive, 12(2), 95-96.

22. Rose, K. (1996, February). The new workforce: Let's be flexible, HR Focus, 73(2), 16.

23. Sopranos, K. (1998, November 29). Merry Christmas! You're fired. Chicago Tribune, p. 1.

24. Tepper, B. (2000). Consequences of Abusive Supervision, Academy of Management Journal, 43(2), 178-190.

25. Wendt, A. C., \& Slonaker, W.M. (1992, May). Discrimination reflects on you. HR Magazine, 44-47.

26. Wilson, B. C. (1991, July). U.S. businesses suffer from workplace trauma. Personnel Journal, 47-50. ABI/Inform (1998, June). CD-ROM. Information Access.

27. Working mothers need more than just creches (1997, October). Management Today, 8.

28. Wyatt, J. \& Hare, C. (1998). Work abuse: The missing link to child abuse (p.1). Schenkman Books.

29. Verespej, M. A. (1997, January). Zero tolerance. Industry Week, 7, 24-28. ABI/Inform(1998, July). CD-ROM. Information Access.

30. Vine, P. (1997, November-December). Battling the myth of the superwoman. British Journal of Administrative Management, 12-13. 